\section{Wulff Possart in Frankreich ausgezeichnet}

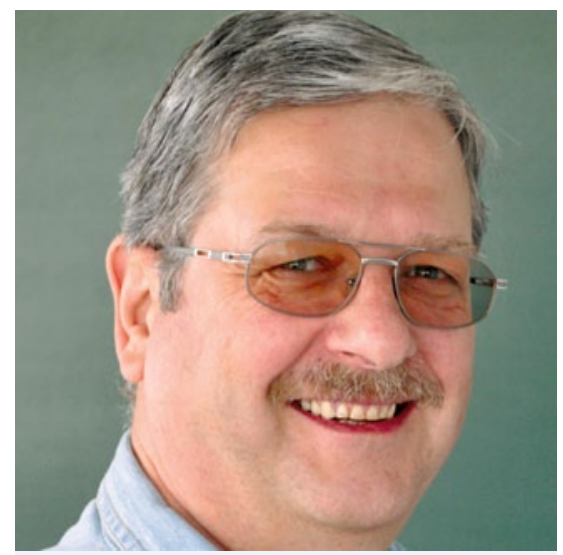

Prof. Wulff Possart wurde von der französischen Adhäsionsgesellschaft mit dem „Prix Dedale 2013“ ausgezeichnet.
$\mathrm{P}_{\mathrm{s}}^{\mathrm{ram}}$ ofessor Wulff Possart, Inhaber des Lehrstuhls Adhäsion und Interphasen in Polymeren an der Universität des Saarlandes, wurde von der französischen Adhäsionsgesellschaft für die Gesamtheit seiner wissenschaftlichen Beiträge auf dem Gebiet der Adhäsionsforschung mit dem „Prix Dedale 2013“ ausgezeichnet. Verliehen wurde ihm dieser international begehrte Preis bereits am 6. Dezember 2013 auf den jährlich stattfindenden „Journées d‘Etude sur l'Adhesion“. Der renommierte „Prix Dedale“, der seit Gründung der Gesellschaft Anfang der 1990er Jahre alle zwei Jahre verliehen wird, ist nicht die erste Würdigung, die Wulff Possart für seine herausragenden Leistungen auf dem Gebiet der Adhäsionsforschung zuteilwurde. Im Jahr 2012 erhielt er als erster deutscher Wissenschaftler eine hohe US-amerikanische Auszeichnung - den „Award for Excellence in Adhesion Science“. Außerdem ist Possart Träger der Wake Memorial Medal, die ihm die Britische Society for Adhesion and Adhesives im Jahr 2008 verlieh.

\title{
Isolierte Herstellung komplexer Silikon-Materialien
}

$\mathrm{B}$ ei der Herstellung silikonhaltiger Produkte können Kontaminationen einen negativen Einfluss auf die Produktion silikonfreier Materialien ausüben und somit zu Qualitätsproblemen führen. Um dies sicher zu vermeiden, empfiehlt sich die Produktion und Abfüllung silikonhaltiger Produkte an einem isolierten Standort.

Das Unternehmen Loop, Lohnhersteller flüssiger, pastöser sowie pulverförmiger Stoffe, hat bereits im Jahr 2012 in einen völlig separaten Standort für die Herstellung silikonhaltiger Materialien investiert. Damit wird der chemischen Industrie die Möglichkeit geboten, bei Bedarf die Produktion silikonhaltiger Produkte auszulagern, um so Kontaminationsprobleme zu vermeiden.

Loop baut die produktionstechnischen Anlagen kontinuierlich aus, sodass zukünftig auch sehr komplexe Silikonformulierungen verarbeitet werden können.

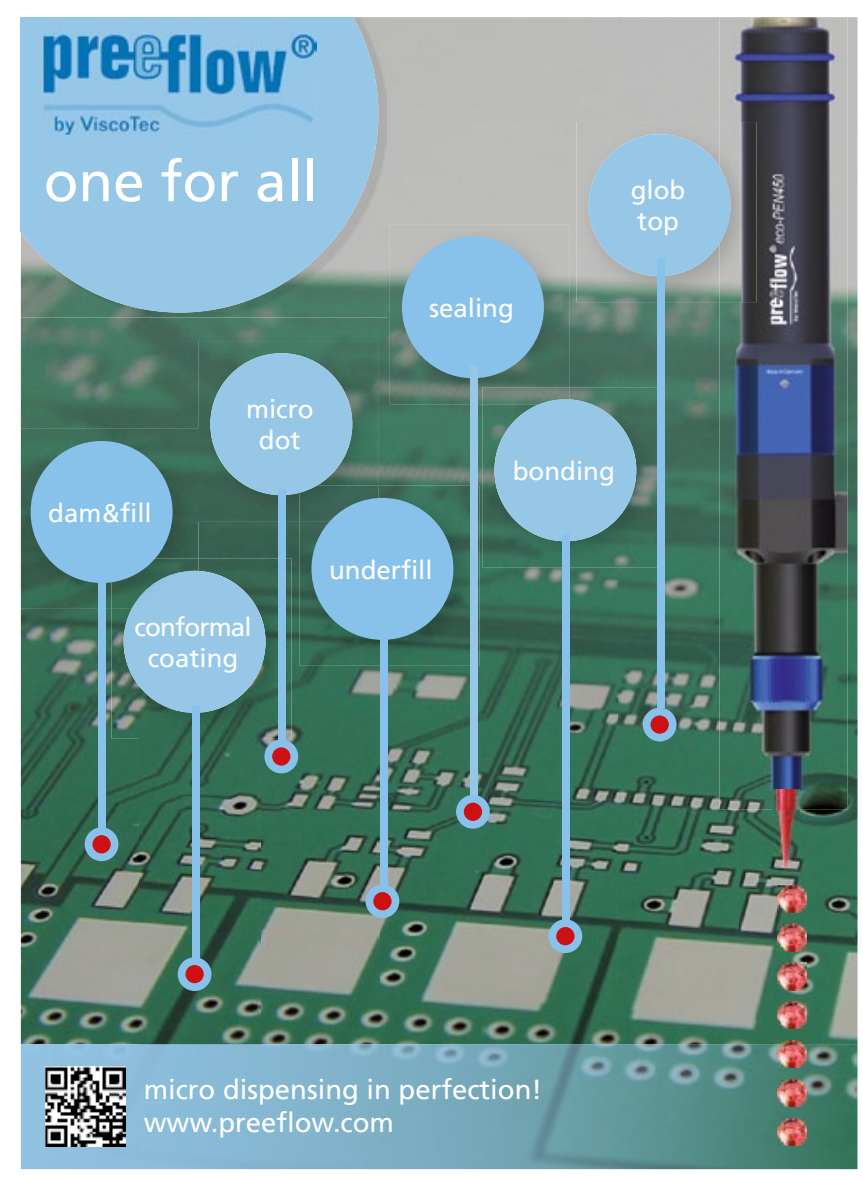

